\title{
An Investigation of the Reaction Pathway for Ethylene Hydrogenation on Pd(111)
}

\author{
D. Stacchiola, S. Azad, L. Burkholder, and W. T. Tysoe* \\ Department of Chemistry and Laboratory for Surface Studies, University of Wisconsin-Milwaukee, \\ Milwaukee, Wisconsin 53211
}

Received: July 5, 2001; In Final Form: September 5, 2001

\begin{abstract}
The hydrogenation of ethylene on $\operatorname{Pd}(111)$ is probed using a combination of temperature-programmed desorption (TPD) and reflection-absorption infrared spectroscopy (RAIRS). Ethylene adsorbs on clean $\operatorname{Pd}(111)$ in a di- $\sigma$ configuration but converts to $\pi$-bonded species when the surface is presaturated by hydrogen. Ethane is formed with an activation energy of $3.0 \pm 0.3 \mathrm{kcal} / \mathrm{mol}$ only when $\mathrm{Pd}(111)$ is pre-covered by hydrogen and not when ethylene and hydrogen are co-dosed, indicating that ethylene blocks hydrogen adsorption. Experiments performed by grafting ethyl species onto the surface by reaction with ethyl iodide indicate that ethyl species hydrogenate much more rapidly than the overall rate of ethylene hydrogenation, demonstrating that the addition of the first hydrogen atom to adsorbed ethylene to form an ethyl species is the rate-limiting step in the hydrogenation reaction. The adsorption geometry of ethyl iodide is found to depend on dosing conditions. When adsorbed at low exposures at $80 \mathrm{~K}$, the mirror symmetry plane of ethyl iodide is oriented close to parallel to the surface. At higher exposures, it adopts a geometry in which the symmetry plane is closer to perpendicular to the surface.
\end{abstract}

\section{Introduction}

It is now well established that transition-metal-catalyzed double- and triple-bond hydrogenation reactions proceed in a stepwise fashion via the so-called Horiuti-Polanyi model. ${ }^{1}$ In the case of acetylene hydrogenation to ethylene catalyzed by $\operatorname{Pd}(111)$, it was shown, by grafting vinyl intermediates onto the surface using vinyl iodide, that the addition of the first hydrogen to acetylene to form the vinyl intermediate was rate-limiting in the overall reaction pathway and that the second hydrogenation step was fast. ${ }^{2}$ This result was in accord with the observation that the rate of acetylene hydrogenation to ethylene monitored using temperature-programmed desorption on $\operatorname{Pd}(111)$ was proportional to the coverage of hydrogen atoms on the surface. ${ }^{3}$ This methodology is extended in this work to examining $\operatorname{Pd}(111)$-catalyzed ethylene hydrogenation. Here, stepwise addition of hydrogen to ethylene proceeds via an ethyl intermediate which would then react with a second hydrogen to form ethane. The rate-limiting step is probed by forming ethyl species on the surface by exposing it to ethyl iodide. The surface species are characterized using reflection-absorption infrared spectroscopy (RAIRS) and the surface reaction kinetics monitored using temperature-programmed desorption (TPD).

\section{Experimental Section}

Experiments were carried out in three stainless steel ultrahigh vacuum chambers operating at base pressures of less than $1 \times$ $10^{-10}$ Torr following bakeout, and which have been described in detail elsewhere. ${ }^{4-6}$

Infrared data were collected from a palladium single crystal sample mounted in a modified $23 / 4$-in. six-way cross equipped with infrared-transparent $\mathrm{KBr}$ windows. The sample could be

* Author to whom correspondence should be addressed. Phone: (414) 229-5222. Fax: (414) 229-5036. E-mail: wtt@uwm.edu. resistively heated to $1200 \mathrm{~K}$ or cooled to $80 \mathrm{~K}$ using liquid nitrogen. Infrared spectra were collected using a Bruker Equinox infrared spectrometer and a liquid-nitrogen-cooled, mercury cadmium telluride detector. The complete light path was enclosed and purged with dry, $\mathrm{CO}_{2}$-free air. Data were typically collected for 1000 scans at $4 \mathrm{~cm}^{-1}$ resolution.

Molecular beam experiments were carried out in a second system comprising an 8-in.-diameter, stainless-steel vacuum chamber pumped by means of a 6-in.-diameter, liquid-nitrogentrapped diffusion pump (pumping speed $850 \mathrm{~L} / \mathrm{s}$ ). This configuration was selected to maximize the pumping speed compared to the chamber volume to minimize the background pressure when the beam is operating. A diffusion pump also provides the throughput necessary for a molecular beam apparatus where gas is continually leaked into the system. The $\operatorname{Pd}(111)$ sample is mounted to a carousel geometry manipulator which allows the sample to be moved in and out of the beam. The sample can also be resistively heated to $1200 \mathrm{~K}$ and cooled to $80 \mathrm{~K}$ by thermal contact to a liquid-nitrogen-filled reservoir. The chamber also houses a quadrupole mass spectrometer which is mounted on a flange on a nipple attached to the side of the chamber so that the mass spectrometer is not in line of sight of the sample. The quadrupole mass spectrometer is under computer control and can sequentially monitor the intensity of up to five masses. This is used for temperature-programmed desorption experiments and for measuring the background pressure during a molecular beam experiment. Background pressures are also monitored by a nude ionization gauge located in the chamber and all pressures are uncorrected for ionization gauge sensitivity.

Temperature-programmed desorption spectra were collected in a third chamber operating at base pressure of $5 \times 10^{-11}$ Torr following bakeout which is pumped by a combination of ion and sublimation pumps. The sample is also mounted to a carousel geometry manipulator and can be placed close to, and in line of site of, the ionizer of a Dichor quadrupole mass 


\section{Ethylene Hydrogenation on $\mathrm{Pd}(111)$}

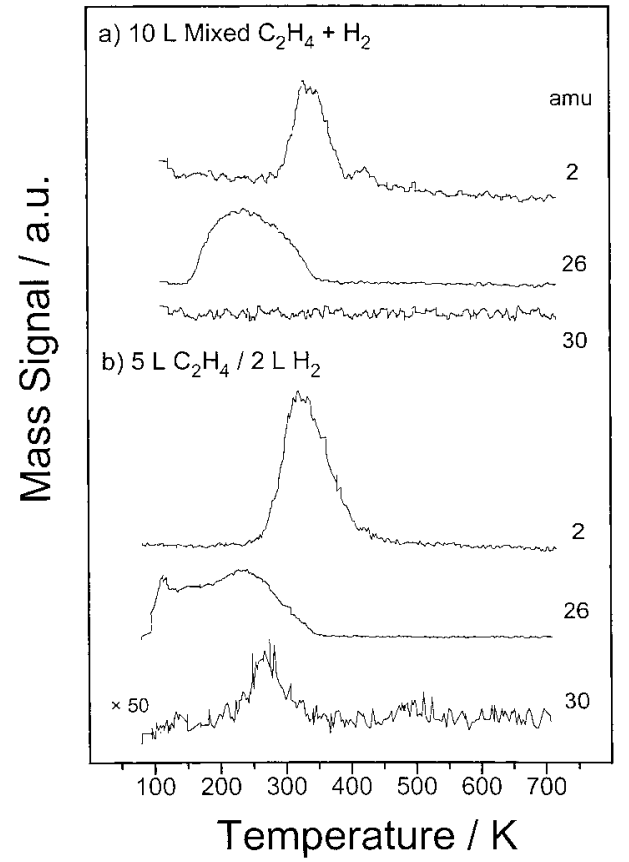

Figure 1. Temperature-programmed desorption spectra collected at 2 amu $\left(\mathrm{H}_{2}\right), 26 \mathrm{amu}$ (ethylene), and $30 \mathrm{amu}$ (ethane) of (a) $10 \mathrm{~L}$ exposure of an equimolar mixture of ethylene and hydrogen, and (b) $2 \mathrm{~L}$ of $\mathrm{H}_{2}$ followed by $5 \mathrm{~L}$ of ethylene, on $\mathrm{Pd}(111)$.

spectrometer, also interfaced to a computer and capable of collecting five masses sequentially during the desorption sweep.

The $\operatorname{Pd}(111)$ sample is cleaned using a standard procedure which consists of heating at $1000 \mathrm{~K}$ in $\sim 4 \times 10^{-8}$ Torr of oxygen and then annealing at $1200 \mathrm{~K}$ in vacuo to remove any remaining oxygen. Since the carbon KLL Auger feature is effectively obscured by a strong palladium peak, Auger spectroscopy is not particularly sensitive to the presence of small amounts of carbon on the surface. It was found that a more sensitive gauge of carbon coverage was to saturate the surface with oxygen and to perform a temperature-programmed desorption experiment. The presence of surface carbon is manifest by the desorption of $\mathrm{CO}$. As the surface becomes depleted of carbon, the $\mathrm{CO}$ yield decreases and the yield of oxygen increases correspondingly in intensity. The complete absence of carbon is indicated by the desorption of only $\mathrm{O}_{2}$.

Ethylene (Matheson) and hydrogen (Gas Tech, CP Grade) were transferred to glass bottles and attached to the gas-handling system of the vacuum chambers. Ethylene was further purified by several freeze-pump-thaw cycles. Ethyl iodide (Acros, 98\% purity) was transferred to a glass vial and cleaned using several freeze-pump-thaw cycles. The deuterium (Linde, CP Grade) was used as received. The cleanliness of all reactants was monitored mass spectroscopically.

\section{Results}

Shown in Figure 1 is a series of temperature-programmed desorption spectra obtained either by co-dosing ethylene and hydrogen (Figure 1a) or by sequentially dosing hydrogen and then ethylene (Figure 1b). When equimolar amounts of ethylene and hydrogen are co-dosed on the surface, no ethane desorption is detected and hydrogen desorbs at $\sim 360 \mathrm{~K}$ due to the recombination of hydrogen atoms on the $\mathrm{Pd}(111)$ surface. $^{7}$ Ethylene desorbs molecularly in a broad feature centered at

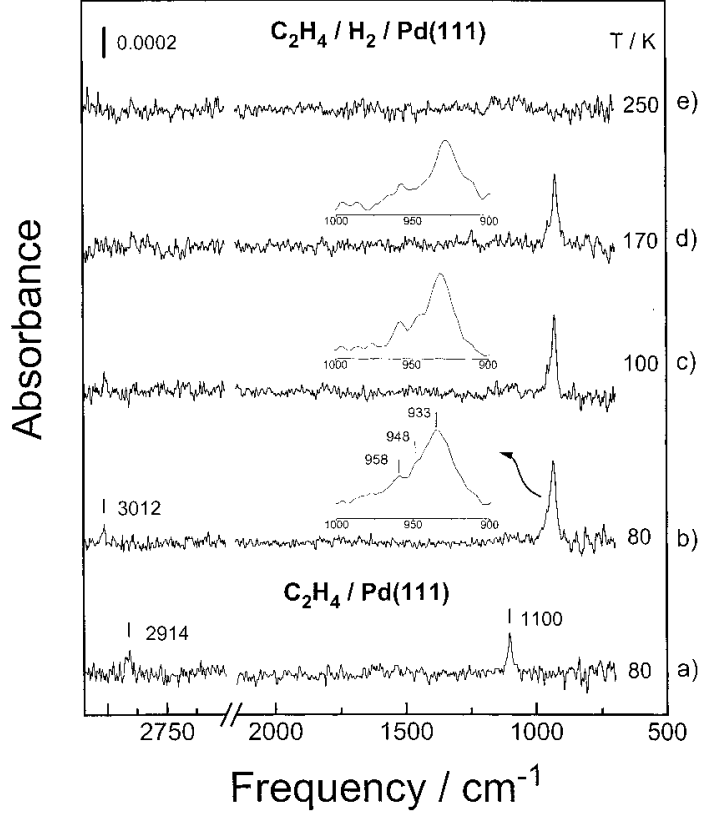

Figure 2. Reflection-absorption infrared spectra of (a) $5 \mathrm{~L}$ of ethylene adsorbed on clean $\mathrm{Pd}(111)$ at $80 \mathrm{~K}$ and $(\mathrm{b}-\mathrm{e}) 5 \mathrm{~L}$ of ethylene adsorbed on a surface predosed with $2 \mathrm{~L} \mathrm{H}_{2}$ and annealed to various temperatures. The annealing temperatures are displayed adjacent to the corresponding spectrum.

$\sim 230 \mathrm{~K}$ in a profile that is essentially identical to that found in the absence of hydrogen. ${ }^{8}$ In contrast, when the surface is first dosed with $2 \mathrm{~L}$ of hydrogen $\left(1 \mathrm{~L}\right.$ (Langmuir) $=1 \times 10^{-6}$ Torr s), and then dosed with $5 \mathrm{~L}$ of ethylene, a small amount of ethane desorption is detected at $\sim 270 \mathrm{~K}$. Note that the amount of ethane formed by ethylene hydrogenation is significantly less than the corresponding temperature-programmed desorption yield of ethylene from the hydrogenation of acetylene on $\operatorname{Pd}(111){ }^{3}$ Hydrogen desorbs at $\sim 330 \mathrm{~K}$, again due to the recombination of hydrogen atoms on the surface. However, despite the lower hydrogen exposure in the spectra of Figure $1 \mathrm{~b}$ compared to that in Figure 1a $(2 \mathrm{~L}$ compared to $5 \mathrm{~L})$, the desorption yield of hydrogen is lower when ethylene and hydrogen are co-dosed. This indicates that ethylene blocks hydrogen adsorption on $\operatorname{Pd}(111)$. A similar effect has been found on $\mathrm{Pt}(111)^{9}$ and $\mathrm{Pd} / \mathrm{Al}_{2} \mathrm{O}_{3} / \mathrm{NiAl}(110) .{ }^{10} \mathrm{In}$ addition, the ethylene desorption profile has been substantially modified by the presence of a hydrogen overlayer so that, in addition to consisting of a broad feature centered at $\sim 230 \mathrm{~K}$, it also exhibits a small feature at $\sim 120 \mathrm{~K}$. Temperature-programmed desorption spectra were also collected for ethylene adsorbed on deuterium-precovered $\mathrm{Pd}(111)$ (not shown). These spectra revealed the formation of ethane at $\sim 270 \mathrm{~K}$ with the maximum mass at $32 \mathrm{amu}$ (corresponding to $\mathrm{C}_{2} \mathrm{H}_{4} \mathrm{D}_{2}$ ) indicating that two adsorbed deuterium atoms add to the ethylene double bond in accord with the Horiuti-Polanyi pathway, ${ }^{1}$ and that the extent of exchange between adsorbed hydrogen and ethylene is negligible.

Surface science studies have shown that more open crystal faces are generally more active for hydrogenation than closepacked surfaces. ${ }^{11}$ Sekitani et al. ${ }^{12}$ found that a $\operatorname{Pd}(110)$ surface formed ethane by self-hydrogenation of ethylene and that the ethane production increased with addition of hydrogen to the surface. In accord with this view, we found only ethane when the surface was first saturated with hydrogen on the close-packed (111) face of palladium.

Figure 2 shows the reflection-absorption infrared spectra for ethylene (5 L) adsorbed on clean $\mathrm{Pd}(111)$ at $80 \mathrm{~K}$ (Figure 2a). 
Arrhenius Plot of $\mathrm{C}_{2} \mathrm{H}_{4} / \mathrm{H}_{2} / \mathrm{Pd}(111)$

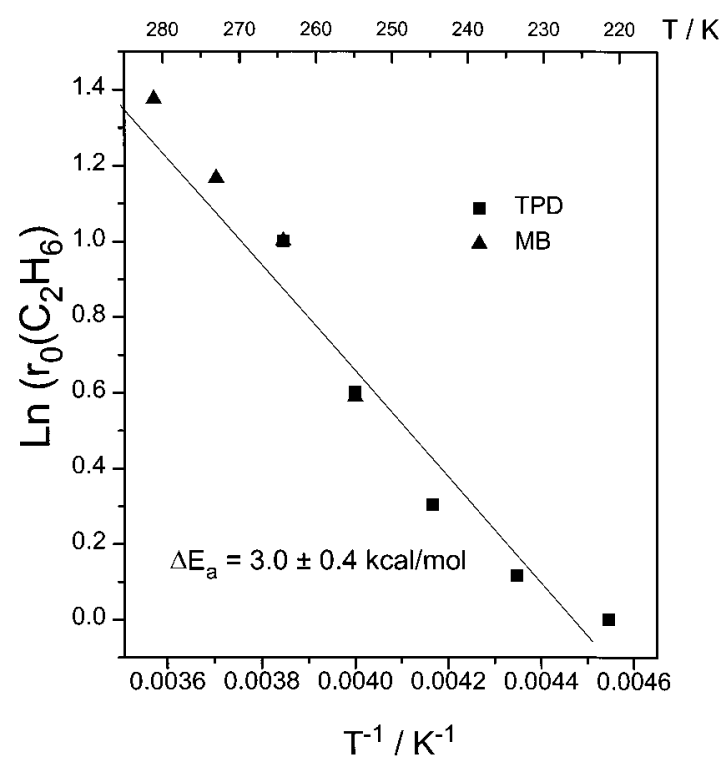

Figure 3. An Arrhenius plot of the leading edge region of the temperature-programmed desorption data shown in Figure 1 (ם) compared with results obtained using molecular beams ( $\mathbf{\Lambda})$ for scattering of ethylene from hydrogen-covered $\operatorname{Pd}(111)$.

Also shown are a series of spectra for ethylene $(5 \mathrm{~L})$ adsorbed on hydrogen precovered ( $2 \mathrm{~L} \mathrm{H}_{2}$ exposure) $\mathrm{Pd}(111)$ at $80 \mathrm{~K}$, and annealed to various temperatures. The annealing temperatures are indicated adjacent to the corresponding spectrum. The spectra for ethylene on clean and hydrogen-covered $\operatorname{Pd}(111)$ are significantly different, indicating that the presence of preadsorbed hydrogen substantially affects the adsorption of ethylene. Ethylene adsorbed on clean $\mathrm{Pd}(111)$ exhibits two features at 1100 and $2914 \mathrm{~cm}^{-1}$, while pre-covering the surface with hydrogen causes the $1100-\mathrm{cm}^{-1}$ feature to shift to $933 \mathrm{~cm}^{-1}$ and the $2914-\mathrm{cm}^{-1}$ feature to move to $3012 \mathrm{~cm}^{-1}$. The $933-$ $\mathrm{cm}^{-1}$ peak for ethylene on $\mathrm{H} / \mathrm{Pd}(111)$ is relatively broad (Figure $2 b-d)$ and expanded depictions of this feature are displayed above the corresponding spectrum. This reveals that the 933$\mathrm{cm}^{-1}$ feature comprises a manifold of peaks at 933, 948, and $958 \mathrm{~cm}^{-1}$ (Figure 2b). Heating to $100 \mathrm{~K}$ causes the $948-\mathrm{cm}^{-1}$ peak to decrease slightly in intensity while the 933- and 958$\mathrm{cm}^{-1}$ peaks are unaffected. Both the $948-$ and $3012-\mathrm{cm}^{-1}$ peaks disappear completely on heating to $170 \mathrm{~K}$, while the 958 - and $933-\mathrm{cm}^{-1}$ features are only minimally attenuated by heating to this temperature. This suggests the presence of two ethylenederived species on $\mathrm{H} / \mathrm{Pd}(111)$, one with frequencies at 3012 and $948 \mathrm{~cm}^{-1}$ and the other with peaks at 933 and $958 \mathrm{~cm}^{-1}$. All features disappear completely on heating to $250 \mathrm{~K}$.

A reaction activation energy for ethylene hydrogenation can be estimated from the leading-edge region of the ethane (30 amu) desorption profile in the spectrum of Figure 1. The advantage of this method is that it does not rely on any assumptions regarding the reaction order or the value of the preexponential factor. The value of $\ln \left(r_{0}\left(\mathrm{C}_{2} \mathrm{H}_{6}\right)\right)$ measured in this way is plotted versus $1 / T$ in Figure $3(\boldsymbol{\square})$. The hydrogenation of ethylene was also measured using a dc molecular beam from the initial rate of ethane formation when a hydrogen-covered $\operatorname{Pd}(111)$ surface is exposed to a beam of ethylene at various temperatures. An activation energy can also be estimated for this reaction and $\ln \left(\mathrm{r}_{0}\left(\mathrm{C}_{2} \mathrm{H}_{6}\right)\right)$ is also shown plotted versus $1 / T$ in Figure $3(\boldsymbol{\Delta})$. Note that the two sets of data have been normalized for reaction at $265 \mathrm{~K}$ where the ordinate was arbitrarily set to unity. The slopes of both sets of data are in
RAIRS of 1-iodoethane / $\mathrm{Pd}(111)$

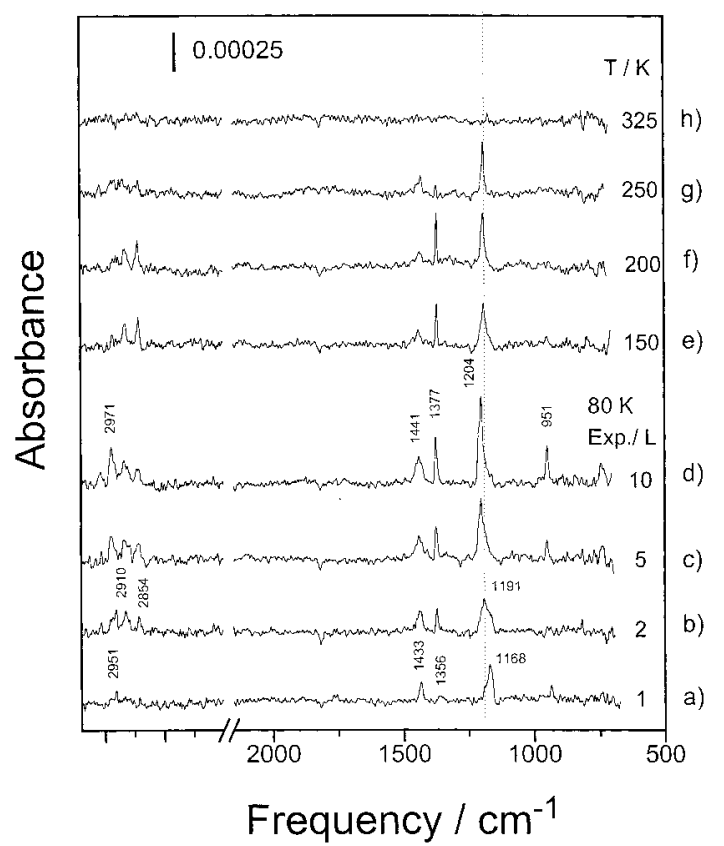

Figure 4. Infrared spectrum of ethyl iodide adsorbed on $\operatorname{Pd}(111)$ as a function of exposure at $80 \mathrm{~K}(\mathrm{a}-\mathrm{d})$ and subsequently heated to various temperatures $(\mathrm{e}-\mathrm{h})$. The exposures and annealing temperatures are displayed adjacent to the corresponding spectrum.

good agreement and yield a value of the reaction activation energy of $3.0 \pm 0.3 \mathrm{kcal} / \mathrm{mol}$. Note that this value is lower than that found for catalytic ethylene hydrogenation on supported palladium between 6.5 and $10.7 \mathrm{kcal} / \mathrm{mol}^{13}$ These values are in good agreement with activation energy measurements for ethylene hydrogenation catalyzed by a palladium foil at high pressures, of $\sim 8.3 \mathrm{kcal} / \mathrm{mol}^{14}$ A similar effect has been noted for acetylene hydrogenation where the activation energy measured on the clean single crystal in temperature-programmed desorption is much lower than that for catalytic acetylene hydrogenation, ${ }^{15}$ and also for $\mathrm{Pt}(111)$-catalyzed ethylene hydrogenation where the activation energy is $10.8 \mathrm{kcal} / \mathrm{mol}$ at high pressures ${ }^{16}$ but $\sim 6 \mathrm{kcal} / \mathrm{mol}$ when measured using molecular beams in ultrahigh vacuum. ${ }^{9}$

According to the Horiuti-Polanyi model, ${ }^{1}$ the formation of ethane by reaction with hydrogen must necessarily proceed via an intermediate ethyl species. The observations that $\mathrm{C}_{2} \mathrm{H}_{6}$ is formed by reaction of $\mathrm{C}_{2} \mathrm{H}_{4}$ with adsorbed atomic hydrogen (Figure 1) and that $\mathrm{C}_{2} \mathrm{H}_{4} \mathrm{D}_{2}$ is formed on a deuterium-precovered surface are in accord with this view. To probe the addition of hydrogen with an adsorbed ethyl species, and to follow the reaction pathway of this intermediate, we have followed a common strategy of grafting intermediates onto the surface using an iodine-containing precursor, in this case, ethyl iodide. ${ }^{17}$ The infrared spectra of ethyl iodide adsorbed on $\operatorname{Pd}(111)$ are displayed in Figure 4 as a function of exposure, and then after annealing the sample to various temperatures, where the annealing temperatures and exposures are marked adjacent to the corresponding spectra. Both the peak positions and relative intensities of the features change as a function of exposure, an effect that has been noted previously for ethyl iodide adsorption on $\mathrm{Pt}(111) .{ }^{17}$ Since the frequencies change only slightly from those of the multilayer, they can be assigned by comparison with the pure compound. ${ }^{18,19}$ The assignments for the multilayer (after $10 \mathrm{~L}$ exposure at $80 \mathrm{~K}$ ) are made in Table 1, where the agreement with the spectrum of the liquid is good. 
TABLE 1: Comparison of the Vibrational Frequencies $\left(\mathrm{cm}^{-1}\right)$ for a Condensed Layer of Methyl Iodide on Pd(111) with the Infrared Spectrum of the Liquid

\begin{tabular}{lcc}
\hline \multicolumn{1}{c}{ mode $^{a}$} & $\begin{array}{c}\text { liquid } \\
\text { frequency }\end{array}$ & $\begin{array}{c}\text { multilayer } \\
\text { frequency/Pd(111) }\end{array}$ \\
\hline$\nu_{\mathrm{a}}\left(\mathrm{CH}_{2}\right) ; \mathrm{A}^{\prime \prime}$ & 3014 & 3018 \\
$\nu_{\mathrm{a}}\left(\mathrm{CH}_{2}\right), \nu_{\mathrm{a}}\left(\mathrm{CH}_{3}\right) ; \mathrm{A}^{\prime}, \mathrm{A}^{\prime \prime}$ & 2972 & 2971 \\
$\nu_{\mathrm{s}}\left(\mathrm{CH}_{3}\right) ; \mathrm{A}^{\prime}$ & 2918 & 2910 \\
$2 \delta_{\mathrm{a}}\left(\mathrm{CH}_{3}\right) ; \mathrm{A}^{\prime}$ & 2862 & 2854 \\
$\delta_{\mathrm{a}}\left(\mathrm{CH}_{3}\right), \delta\left(\mathrm{CH}_{2}\right) ; \mathrm{A}^{\prime}, \mathrm{A}^{\prime \prime}$ & 1452,1437 & 1441 \\
$\delta_{\mathrm{s}}\left(\mathrm{CH}_{3}\right)+v\left(\mathrm{C}-\mathrm{C}^{\prime} ; \mathrm{A}^{\prime}\right.$ & 1377 & 1377 \\
$\omega\left(\mathrm{CH}_{2}\right)+\rho\left(\mathrm{CH}_{3}\right) ; \mathrm{A}^{\prime}$ & 1203 & 1204 \\
$\rho\left(\mathrm{CH}_{3}\right)+v(\mathrm{C}-\mathrm{C}) ; \mathrm{A}^{\prime}$ & 952 & 951 \\
${ }^{a} \omega$, wag; $v$, stretch; $\rho$, rock$; \delta$, scissor. &
\end{tabular}

TABLE 2: Frequencies $\left(\mathrm{cm}^{-1}\right)$ and Relative Intensities for Ethyl Iodide Adsorbed on Pd(111) at Low Exposures (1 L) and after Annealing a Multilayer-Covered Surface to $150 \mathrm{~K}$

\begin{tabular}{|c|c|c|c|}
\hline mode $^{a}$ & $\begin{array}{c}\mathrm{C}_{2} \mathrm{H}_{5} \mathrm{I} / \mathrm{Pd}(111) \\
1 \mathrm{~L} \text { exposure }\end{array}$ & $\begin{array}{c}\mathrm{C}_{2} \mathrm{H}_{5} \mathrm{I} / \mathrm{Pd}(111) \\
10 \mathrm{~L} \text { exposure, } \\
\text { annealed to } \\
150 \mathrm{~K}\end{array}$ & $I(1) / I(2)^{b}$ \\
\hline \multicolumn{4}{|l|}{$v_{\mathrm{a}}\left(\mathrm{CH}_{2}\right) ; \mathrm{A}^{\prime \prime}$} \\
\hline $\begin{array}{l}v_{\mathrm{a}}\left(\mathrm{CH}_{2}\right), v_{\mathrm{a}}\left(\mathrm{CH}_{3}\right) ; \mathrm{A}^{\prime}, \mathrm{A}^{\prime \prime} \\
v_{\mathrm{S}}\left(\mathrm{CH}_{3}\right) ; \mathrm{A}^{\prime}\end{array}$ & 2951 & 2910 & 0 \\
\hline $2 \delta_{\mathrm{a}}\left(\mathrm{CH}_{3}\right) ; \mathrm{A}^{\prime}$ & & 2854 & 0 \\
\hline$\delta_{\mathrm{a}}\left(\mathrm{CH}_{3}\right), \delta\left(\mathrm{CH}_{2}\right) ; \mathrm{A}^{\prime}, \mathrm{A}^{\prime \prime}$ & 1433 & 1441 & 1.2 \\
\hline$\delta_{\mathrm{s}}\left(\mathrm{CH}_{3}\right)+v(\mathrm{C}-\mathrm{C}) ; \mathrm{A}^{\prime}$ & 1356 & 1377 & 0.125 \\
\hline$\omega\left(\mathrm{CH}_{2}\right)+\rho\left(\mathrm{CH}_{3}\right) ; \mathrm{A}^{\prime}$ & 1168 & 1204 & 0.84 \\
\hline
\end{tabular}

${ }^{a} \omega$, wag; $v$, stretch; $\rho$, rock; $\delta$, scissor. ${ }^{b} I(1) / I(2)$ is the intensity ratio of the features for $1 \mathrm{~L}$ of ethyl iodide to that for a multilayer annealed to $150 \mathrm{~K}$.

It is striking that the spectrum of ethyl iodide adsorbed on $\operatorname{Pd}(111)$ at low exposures is different to that after the sample has been heated to $150 \mathrm{~K}$ to remove the multilayer (Figure 4). The frequencies are slightly shifted from each other. However, the major differences are the very different relative intensities. The frequencies and intensities are summarized in Table 2 and will be discussed in greater detail below. The spectrum formed by annealing the multilayer-covered sample persists as the sample is heated to $200 \mathrm{~K}$ but changes substantially as the sample is heated to $250 \mathrm{~K}$ where the $1377-\mathrm{cm}^{-1}$ feature disappears almost completely, and the $\mathrm{C}-\mathrm{H}$ stretching modes are significantly attenuated. Heating to $325 \mathrm{~K}$ causes all of the surface features to disappear completely, connoting complete thermal decomposition of surface molecular species.

The 28-amu temperature-programmed desorption spectra are displayed in Figure 5 following ethyl iodide adsorption at 80 K. Ethyl iodide exposures are displayed adjacent to the corresponding spectrum. A 28-amu feature is detected at low exposures $(0.46 \mathrm{~L})$ centered at $270 \mathrm{~K}$. This feature grows and shifts slightly to lower temperatures $(255 \mathrm{~K})$ as the exposure increases. Desorption spectra were also collected at 26 and 27 amu following an ethyl iodide exposure of $0.46 \mathrm{~L}$ and their desorption profiles exactly mirror the 28 -amu signal. In addition, their relative intensities agree with the mass spectrometer ionizer fragmentation pattern of ethylene measured using the same mass spectrometer by back-filling the chamber with ethylene. From the ethylene desorption temperature of $270 \mathrm{~K}$, and using the experimental heating rate of $7 \mathrm{~K} / \mathrm{s}$, and assuming a preexponential factor of $1 \times 10^{13} \mathrm{~s}^{-1}$, yields a reaction activation energy of $16.2 \mathrm{kcal} / \mathrm{mol} .^{20}$ At higher exposures, this feature is due to the desorption of both ethylene and some unreacted ethyl iodide. ${ }^{17}$ For ethyl iodide exposures of $1.74 \mathrm{~L}$ and greater, a sharp feature appears at $\sim 145 \mathrm{~K}$. This corresponds to the exposure at which condensed layers are detected by infrared
Ethyl lodide / Pd(111)

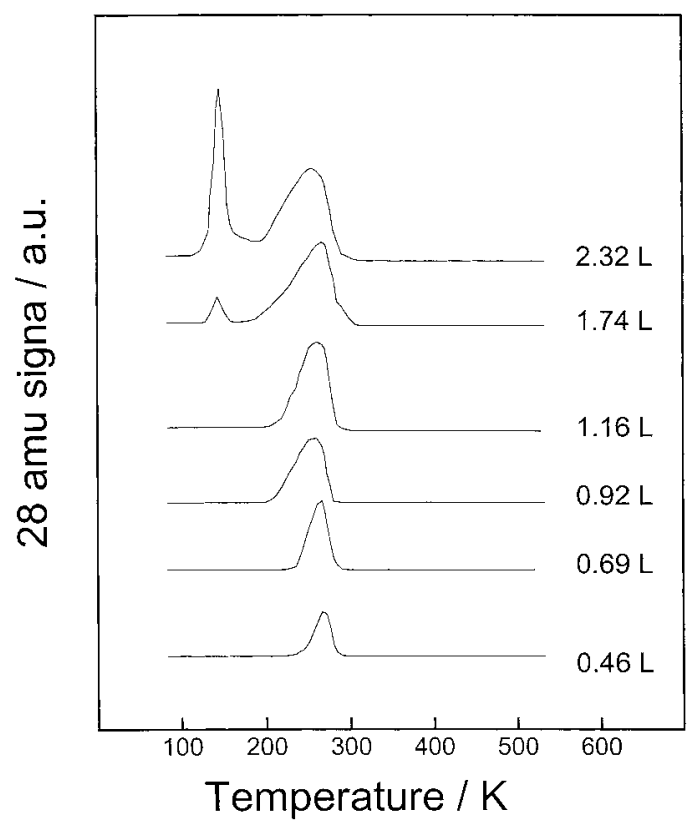

Figure 5. Temperature-programmed desorption spectra of ethyl iodide adsorbed on $\operatorname{Pd}(111)$ collected at $28 \mathrm{amu}$ as a function of ethyl iodide exposure where the ethyl iodide exposures are marked adjacent to the corresponding spectra.

\subsection{Ethyl lodide / $5 \mathrm{~L} \mathrm{D}_{2} / \mathrm{Pd}(111)$}

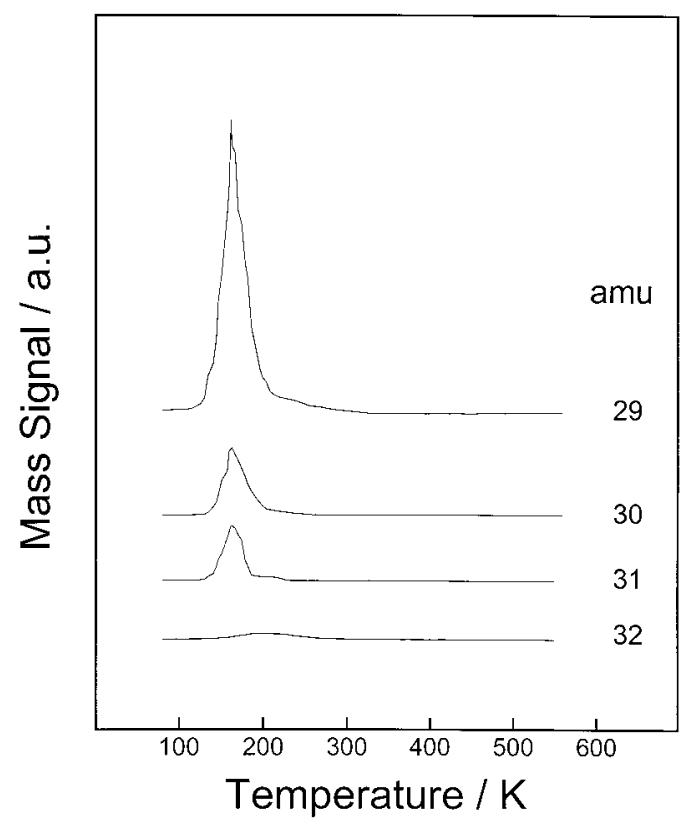

Figure 6. Temperature-programmed desorption spectrum of ethyl iodide $(1.16 \mathrm{~L})$ adsorbed on a deuterium precovered surface (using a deuterium exposure of $5 \mathrm{~L}$ ) collected at various masses. The mass is displayed adjacent to the corresponding spectrum.

spectroscopy (Figure 4, Table 2) and also with the annealing temperature at which it is removed (Figure 4). The other major desorption product is hydrogen which desorbs at $\sim 320 \mathrm{~K}$.

The desorption spectrum of ethyl iodide adsorbed on a deuterium precovered surface monitored at 29, 30, 31, and 32 amu is shown in Figure 6 for a deuterium-saturated surface ( 5 $\mathrm{L}$ exposure) and an ethyl iodide exposure of $1.16 \mathrm{~L}$. This displays a reasonably symmetric peak centered at $160 \mathrm{~K}$. Note that this temperature is significantly lower than that for the addition of hydrogen to ethylene (Figure 1). 
TABLE 3: Infrared Frequencies $\left(\mathrm{cm}^{-1}\right)$ of Ethylene Adsorbed on Clean Pd(111) Compared with the Gas-Phase Values and di- $\sigma$-Bonded Ethylene on $\operatorname{Pt}(111)^{26,27}$

\begin{tabular}{cccc}
\hline mode $^{b}$ & $\begin{array}{c}\text { gas-phase } \\
\text { frequency }\end{array}{ }^{21}$ & $\begin{array}{c}\mathrm{C}_{2} \mathrm{H}_{4} / \mathrm{Pd}(111) \\
\text { (this work) }\end{array}$ & $\begin{array}{c}\mathrm{di}-\sigma \\
\mathrm{C}_{2} \mathrm{H}_{4} / \mathrm{Pt}(111)\end{array}$ \\
\hline $\mathrm{B}_{1 \mathrm{u}}, \omega-\mathrm{CH}_{2}$ & 949 & 1100 & 993 \\
$\mathrm{~A}_{\mathrm{g}}, v(\mathrm{C}-\mathrm{C})$ & 1343 & 1100 & 1047 \\
$\mathrm{~A}_{\mathrm{g}}, \delta-\mathrm{CH}_{2}$ & 1623 & & 1414 \\
$\mathrm{~A}_{\mathrm{g}}, v_{\mathrm{s}}-\mathrm{CH}_{2}$ & 3019 & 2914 & 2903,2910 \\
${ }^{a}$ Gas-phase $D_{2 h}$ symmetry. ${ }^{b} \omega$, wag; $v$, stretch; $\rho$, rock; $\delta$, scissor.
\end{tabular}

\section{Discussion}

Ethylene adsorbs on clean $\operatorname{Pd}(111)$ and exhibits vibrational frequencies at 1100 and $2914 \mathrm{~cm}^{-1}$ (Figure 2). Gas-phase ethylene has $D_{2 d}$ symmetry. ${ }^{21}$ Assuming that it adsorbs with its molecular plane parallel to the $\operatorname{Pd}(111)$ surface, ${ }^{22,23}$ the symmetry is lowered to $C_{2 v}$. Note that this symmetry is maintained even if the carbons rehybridize from $\mathrm{sp}^{2}$ to $\mathrm{sp}^{3}$ as long as the carbon-carbon bonds remains parallel to the surface. In this case, the gas-phase $\mathrm{A}_{\mathrm{g}}$ and $\mathrm{B}_{1 \mathrm{u}}$ irreducible representations in $D_{2 d}$ correlate with $\mathrm{A}_{1}$ in $C_{2 v}$ symmetry. ${ }^{24}$ The gas-phase frequencies for these modes are at 949.2, 1342.4, 1623.3, and $3019.3 \mathrm{~cm}^{-1}$. ${ }^{21}$ The $\mathrm{B}_{2 \mathrm{~g}}$ and $\mathrm{B}_{3 \mathrm{u}}$ representations correlate with $\mathrm{B}_{1}$, and the corresponding gas-phase frequencies are at 943, 1443.5 and $2989.5 \mathrm{~cm}^{-1}$. Finally, $\mathrm{B}_{2 \mathrm{u}}$ correlates with $\mathrm{B}_{2}$ with gas-phase frequencies at 955 and $3105.5 \mathrm{~cm}^{-1}$. Only modes of $\mathrm{A}_{1}$ symmetry are active in RAIRS ${ }^{25}$ so that, in principle, ethylene adsorbed with $C_{2 v}$ symmetry should exhibit four peaks. These are detected on $\mathrm{Pt}(111)$ and the assignments are displayed in Table 3 for di- $\sigma$-bonded ethylene. ${ }^{26,27}$ The infrared spectrum for ethylene on $\operatorname{Pd}(111)$ (Figure 2) exhibits two features at 1100 and $2914 \mathrm{~cm}^{-1}$. The $v_{\mathrm{s}}-\mathrm{CH}_{2}$ mode at $2914 \mathrm{~cm}^{-1}$ (shifted from $3019 \mathrm{~cm}^{-1}$ in the gas phase) is in reasonable agreement with the value for di- $\sigma$-bonded ethylene on $\mathrm{Pt}(111)$ (Table 3). However, rather than detecting two features for the $v(\mathrm{C}=\mathrm{C})$ and $\omega-\mathrm{CH}_{2}$ modes (at 1047 and $993 \mathrm{~cm}^{-1}$ on Pt(111)), only a single feature is detected. The $1414-\mathrm{cm}^{-1}$ feature for $\operatorname{Pt}(111)$ is extremely weak. ${ }^{27}$ It is, however, worthy of note that, for $\pi$-bonded ethylene on silver adsorbed with the molecular plane parallel to the surface, only the $\omega-\mathrm{CH}_{2}$ mode is detected in this region in HREELS ${ }^{28,29}$ and RAIRS. ${ }^{30,31}$ Note that this mode is also detected only on hydrogen-covered $\mathrm{Pd}(111)$ (Figure $2 \mathrm{~b}-$ d). This may imply that the $1100-\mathrm{cm}^{-1}$ peak is due to the $\omega-\mathrm{CH}_{2}$ mode or that the $v(\mathrm{C}-\mathrm{C})$ and $\omega-\mathrm{CH}_{2}$ vibrations are accidentally degenerate. In either case, these results indicate that ethylene is substantially rehybridized on adsorption on clean $\operatorname{Pd}(111)$.

This conclusion appears to contradict previous HREELS, ${ }^{32}$ photoelectron spectroscopic, ${ }^{22}$ and near-edge X-ray absorption fine structure (NEXAFS) data ${ }^{23}$ which indicate that ethylene adsorbed on clean $\mathrm{Pd}(111)$ is not substantially distorted from the gas-phase geometry. These results have also been questioned recently as a result of theoretical studies ${ }^{33}$ which suggest a combination of $\pi$ - and di- $\sigma$-adsorbed ethylene as the most stable surface composition.

The results of Figure 2 indicate that the ethylene structure is strongly affected by the presence of hydrogen on the surface since features are detected at 933 and $3012 \mathrm{~cm}^{-1}$ on hydrogencovered $\operatorname{Pd}(111)$ (Figure 2). These values are close to those found for $\pi$-bonded ethylene on $\operatorname{Pt}(111)^{26,34}$ and silver. ${ }^{28-31}$ The data of Figure 2, however, show that the $933-\mathrm{cm}^{-1}$ peak comprises several features. The features at 948 and $3012 \mathrm{~cm}^{-1}$ disappear on heating to $170 \mathrm{~K}$. This temperature coincides with the sharp desorption state seen in temperature-programmed desorption of $\mathrm{C}_{2} \mathrm{H}_{4} / \mathrm{H} / \mathrm{Pd}(111)$ at $\sim 120 \mathrm{~K}$ (Figure 1). These
TABLE 4: Infrared Frequencies $\left(\mathrm{cm}^{-1}\right)$ of Ethylene Adsorbed on Hydrogen-Covered Pd(111) Compared with the Gas-Phase Values and $\pi$-Bonded Ethylene on $\operatorname{Pt}(111)^{26,34}$

\begin{tabular}{lccc}
\hline \multicolumn{1}{c}{ mode $^{b}$} & $\begin{array}{c}\text { gas-phase } \\
\text { frequency }{ }^{21}\end{array}$ & $\begin{array}{c}\mathrm{C}_{2} \mathrm{H}_{4} / \mathrm{H} / \mathrm{Pd}(111) \\
\text { (this work) }\end{array}$ & $\begin{array}{c}\pi \text {-bonded } \\
\mathrm{C}_{2} \mathrm{H}_{4} / \mathrm{Pt}(111)\end{array}$ \\
\hline $\mathrm{B}_{1 \mathrm{u}}, \omega-\mathrm{CH}_{2}$ & 949 & $933,948,958$ & 954 \\
$\mathrm{~A}_{\mathrm{g}}, \nu(\mathrm{C}-\mathrm{C})$ & 1343 & & \\
$\mathrm{~A}_{\mathrm{g}}, \delta-\mathrm{CH}_{2}$ & 1623 & & \\
$\mathrm{~A}_{\mathrm{g}}, \nu_{\mathrm{s}}-\mathrm{CH}_{2}$ & 3019 & 3012 & 2995 \\
${ }^{a}$ Gas-phase $D_{2 h}$ symmetry. ${ }^{b} \omega$, wag; $\nu$, stretch; $\rho$, rock; $\delta$, scissor.
\end{tabular}

vibrational frequencies are very close to those of gas-phase ethylene (Table 4) and are assigned to undistorted, very weakly bound ethylene. From the peak desorption temperature of 114 $\mathrm{K}$, a Redhead analysis ${ }^{20}$ yields a desorption activation energy of $28 \mathrm{~kJ} / \mathrm{mol}$. This is reasonably close to the value of $40 \pm 10$ $\mathrm{kJ} / \mathrm{mol}$ for $\pi$-bonded ethylene on $\operatorname{Pt}(111){ }^{35}$

The spectrum formed by heating to $170 \mathrm{~K}$ reveals two features at 933 and $958 \mathrm{~cm}^{-1}$. These disappear on heating to $250 \mathrm{~K}$ coincident with the broad $\sim 230 \mathrm{~K}$ ethylene desorption peak (Figure 1). Ethane is also formed in the same temperature range, indicating that the second ethylenic species hydrogenates by reaction with adsorbed hydrogen. The most intense $933-\mathrm{cm}^{-1}$ peak is assigned to the $\omega-\mathrm{CH}_{2}$ mode. A similar structure in this feature has been detected for ethylene on silver ${ }^{31}$ and ascribed to the appearance of the gas-phase $\mathrm{B}_{2 \mathrm{~g}}$ mode $\left(943 \mathrm{~cm}^{-1}\right){ }^{21}$ This correlates with a $\mathrm{B}_{1}$ mode as the symmetry is reduced to $C_{2 v}{ }^{24}$ and transforms as $x$ (which is oriented along the $\mathrm{C}-C$ axis ${ }^{21}$ ). This implies that the $\pi$-bonded ethylene might be slightly tilted so that one carbon is somewhat farther away from the surface than the other. It is clear, however, that preadsorption of hydrogen on $\operatorname{Pd}(111)$ leads to the formation of relatively undistorted ethylenic species. A similar effect has been noted for $\mathrm{Fe}(100)^{36}$ and $\mathrm{Pd} / \mathrm{Al}_{2} \mathrm{O}_{3} / \mathrm{NiAl}(110) .{ }^{10}$ These observations suggest that the photoelectron spectroscopic and NEXAFS data may have been collected for ethylene adsorbed on a hydrogencontaminated surface. It should be noted that palladium, because of its ability to absorb large quantities of hydrogen, is particularly susceptible to hydrogen contamination and great care must be taken to ensure that the background pressure is sufficiently low, and the sample sufficiently carefully cleaned, to exclude all hydrogen.

The data of Figure 1 indicate that ethylene can hydrogenate to ethane on $\operatorname{Pd}(111)$ when the surface has been precovered by hydrogen (Figure 1b) but not when ethylene and hydrogen are co-dosed (Figure 1a). The Arrhenius plot for the hydrogenation rate as a function of temperature (Figure 3) shows that the activation energy for ethylene hydrogenation is $3.0 \pm 0.3 \mathrm{kcal} /$ mol, a value that is substantially lower than the catalytic hydrogenation activation energy found at higher pressures. ${ }^{13,14}$ A similar effect has been found for acetylene hydrogenation to ethylene on $\operatorname{Pd}(111) .{ }^{15}$ Part of the origin of this discrepancy is likely to be the fact that catalytic hydrogenation does not take place on a clean surface but on an ethylidyne-covered catalyst in the case of ethylene hydrogenation, ${ }^{6}$ and a surface comprising a mixed ethylidyne + vinylidene layer for acetylene hydrogenation. ${ }^{37}$ The leading edge of the ethane desorption state depends on the activation energy and preexponential factor for the reaction of atomic hydrogen with adsorbed ethylene. The trailing edge of the ethane (30 amu, Figure 1) desorption state is coincident with the trailing edge of the ethylene ( $26 \mathrm{amu}$, Figure 1) desorption profile. Hydrogen continues to desorb at significantly higher temperatures (where the onset of desorption is at $\sim 280 \mathrm{~K}$ ), suggesting that the trailing edge of the ethane desorption state is due to the loss of ethylene from the surface. 
A similar effect has been observed previously for the hydrogenation of acetylene to ethylene in temperature-programmed desorption ${ }^{3}$ where, in this case, the trailing edge of the ethylene desorption state was due to the loss of adsorbed acetylene which converts into unreactive vinylidene species. ${ }^{38}$ In the case of ethylene adsorbed on $\operatorname{Pd}(111)$, the corresponding conversion of adsorbed ethylene into ethylidyne species is much slower than the rate of ethylene desorption and the infrared spectra of ethylene adsorbed both on hydrogen-precovered and clean $\operatorname{Pd}(111)$ show no evidence for ethylene-to-ethylidyne conversion since the presence of ethylidyne would be clearly indicated by an intense infrared feature at $1329 \mathrm{~cm}^{-1} .6$ This behavior is in contrast to that found on $\mathrm{Pt}(111)$ where ethylidyne is detected, ${ }^{39}$ indicating that the rate of ethylidyne formation on palladium is much slower than that on platinum. Since $\pi$-bonded ethylene is exclusively detected by infrared spectroscopy on hydrogenprecovered $\operatorname{Pd}(111)$ (Figure 2), this suggests that a $\pi$-bonded ethylene species hydrogenates to form ethane. It has been shown previously that, on $\operatorname{Pt}(111), \pi$-bonded ethylene hydrogenates to ethane while the di- $\sigma$ species is inactive. ${ }^{26}$ The results presented here are in accord with this observation.

To probe the rate-limiting step in the hydrogenation of ethylene to ethane, we have investigated the adsorption of ethyl iodide on $\operatorname{Pd}(111)$. The data of Figure 6 indicate that adsorbing ethyl iodide onto a deuterium pre-covered Pd(111) surface yields a maximum mass at 31 amu corresponding to the formation of $\mathrm{d}_{1}$-ethane, suggesting that a single adsorbed deuterium reacts with an adsorbed ethyl group to form ethane, where this reaction occurs at $160 \mathrm{~K}$. If this reaction indeed takes place, this suggest that the rate of ethyl hydrogenation is faster than the rate of formation of ethane by the hydrogenation of ethylene (Figure 1 ), so that the rate at which adsorbed ethylene reacts to form an ethyl species is the rate-limiting step in the stepwise addition of hydrogen. This conclusion is in accord with theoretical work on $\operatorname{Pt}(111){ }^{40}$

The surface properties of adsorbed ethyl iodide on $\operatorname{Pd}(111)$ are summarized in Figures 4 and 5. The infrared data of Figure 4 indicate that a condensed layer of ethyl iodide forms after an exposure of $10 \mathrm{~L}$ and the assignments for the multilayer are displayed in Table 1, showing good agreement with the spectrum of liquid ethyl iodide. ${ }^{18,19}$ The infrared spectrum of ethyl iodide adsorbed on clean $\mathrm{Pd}(111)$ at $80 \mathrm{~K}$ with an exposure of $1 \mathrm{~L}$ (Figure $4 \mathrm{a}$ ), and that formed by heating a condensed layer to $150 \mathrm{~K}$ to remove the multilayer (Figure 4e), have similar vibrational frequencies, but very different relative intensities. This is shown in the data summarized in Table 2 where the intensity ratio designated $I(1) / I(2)$ for the $\delta_{\mathrm{a}}\left(\mathrm{CH}_{3}\right)$ mode (at $1433 \mathrm{~cm}^{-1}$ for a $1 \mathrm{~L}$ exposure at $80 \mathrm{~K}$ and at $1441 \mathrm{~cm}^{-1}$ after desorbing the multilayer) is 1.2 , but is $\sim 0.13$ for the $\delta_{\mathrm{s}}\left(\mathrm{CH}_{3}\right)$ mode (at $1356 \mathrm{~cm}^{-1}$ for the low-exposure surface, and at 1377 $\mathrm{cm}^{-1}$ after desorbing the multilayer). This implies that ethyl iodide adopts different adsorption geometries when adsorbed under these different conditions. A similar conclusion has been arrived at for ethyl iodide adsorbed on $\mathrm{Pt}(111) .{ }^{17}$ The gas-phase point group of ethyl iodide is $C_{s}$ where the $x-y$ plane is the symmetry plane of the molecule. ${ }^{24}$ In this case, modes of $\mathrm{A}^{\prime}$ symmetry transform as $x$ and $y$, vectors oriented in the symmetry plane of ethyl iodide, and modes of $\mathrm{A}^{\prime \prime}$ symmetry transform as $z$, oriented perpendicularly to this plane. ${ }^{24}$ The surface selection rule for RAIRS indicates that only modes that transform as a vector oriented perpendicularly to the surface are infrared active $^{25}$ and can be used to indicate adsorbate orientations. In the case of ethyl iodide adsorbed at low exposures at $80 \mathrm{~K}$, the methyl bending mode of $\mathrm{A}^{\prime \prime}$ symmetry is the most intense while the mode of $\mathrm{A}^{\prime}$ symmetry is relatively weak (Figure 4; Table 2 ). This implies that the normal to the mirror symmetry plane of ethyl iodide is oriented normal to the $\operatorname{Pd}(111)$ surface. That is, the symmetry plane is oriented substantially parallel to the surface. Note that there is some residual intensity for this species at $1356 \mathrm{~cm}^{-1}$, suggesting that the mirror plane axis may be slightly tilted with respect to the surface. This adsorption geometry is confirmed by the methyl stretching modes also with $\mathrm{A}^{\prime}$ symmetry (Figure 4; Table 2). In contrast, the relatively high intensity of the modes of $\mathrm{A}^{\prime}$ symmetry for adsorbed ethyl iodide formed by desorbing the multilayer (Figure 4; Table 2) indicates that the ethyl iodide mirror plane is oriented more nearly perpendicularly to the surface. Again, the relative intensities of the methyl stretching modes are in accord with this proposal. These conclusions are in accord with the geometries found on $\operatorname{Pt}(111) .{ }^{17}$

Further spectroscopic changes occur on heating the sample to $250 \mathrm{~K}$ where the $1377-\mathrm{cm}^{-1}$ feature diminishes significantly in intensity and the stretching modes at 2854 and $2910 \mathrm{~cm}^{-1}$ also decrease. $\mathrm{C}-\mathrm{I}$ bond scission was found using X-ray photoelectron spectroscopy and temperature-programmed desorption between 150 and $200 \mathrm{~K} .{ }^{41,42}$ This conclusion is corroborated by the temperature-programmed desorption data of Figure 5 which show the appearance of a sharp 28-amu feature with a peak desorption temperature of $270 \mathrm{~K}$. Measurement of the intensities at other masses for an ethyl iodide exposure of $0.46 \mathrm{~L}$ indicates that the peak is due to the desorption of ethylene. At higher exposures, a portion of the feature is due to the desorption of unreacted ethyl iodide which desorbs between 200 and $250 \mathrm{~K}$ at saturation. A trend has been proposed in the ethylene desorption temperature where it desorbs at $160 \mathrm{~K}$ on $\mathrm{Ni}(100), 180 \mathrm{~K}$ on $\mathrm{Pd}(100), 180 \mathrm{~K}$ on $\mathrm{Pt}(111)$, and $307 \mathrm{~K}$ on $\mathrm{Au}(111) .{ }^{43}$ The desorption temperature of $270 \mathrm{~K}$ found here is consistent with this trend since ethylene forms more rapidly than on gold but slower than on more open palladium surfaces or close-packed platinum.

An additional feature is found at $145 \mathrm{~K}$ for ethyl iodide exposures of $1.74 \mathrm{~L}$ and larger. This peak continues to grow with increasing ethyl iodide exposure and its desorption temperature coincides with the loss of multilayer ethyl iodide in the infrared spectrum (Figure 4) and is therefore assigned to the desorption of multilayers of ethyl iodide (Table 1).

The formation of ethylene following ethyl iodide adsorption on $\operatorname{Pt}(111)$ has been interpreted as being due to a $\beta$-hydride elimination reaction from the adsorbed ethyl species. ${ }^{43}$ The onset of ethylene desorption is at $\sim 250 \mathrm{~K}$, while the infrared data of Figure 4 show that the formation of surface ethyl species is complete by $250 \mathrm{~K}$ indicating that $\beta$-hydride elimination is the rate-limiting step in the formation of ethylene.

The effect of preadsorbing deuterium on the surface is shown in the data of Figure 6. It shows $\mathrm{d}_{1}$-ethane formation in a peak centered at $\sim 170 \mathrm{~K}$. The incorporation of a single deuterium species into the product confirms that the ethane is formed by the addition of atomic deuterium to an ethyl species. The onset of ethane desorption, in this case, is very close to the temperature at which substantial amounts of ethyl species are formed on the surface (Figure 4). It is therefore not clear whether this desorption state is limited by the rate of hydrogen addition to the surface ethyl species or by the rate of ethyl formation on the surface. In either case, the rate of hydrogen (deuterium) addition to the ethyl species occurs at or below $170 \mathrm{~K}$, a temperature that is much lower than the rate of ethylene hydrogenation on $\mathrm{Pd}(111)$ in temperature-programmed desorption (Figure 1). This indicates that the addition of the first 
hydrogen to an adsorbed $\pi$-bonded ethylene to form an ethyl species is much slower than the rate of subsequent hydrogenation to form ethane. The surface reaction pathway on clean $\operatorname{Pd}(111)$ can be summarized as follows:

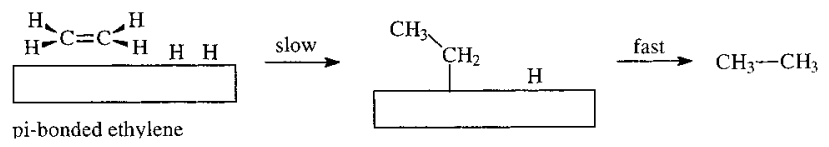

\section{Conclusions}

Ethylene rehybridizes following adsorption on clean $\mathrm{Pd}(111)$. The presence of preadsorbed hydrogen on the surface affects the ethylene adsorption geometry so that it becomes $\pi$-bonded. A small amount of ethane desorption is found in temperatureprogrammed desorption when the surface is precovered by hydrogen, but not when hydrogen and ethylene are co-dosed, indicating that ethylene blocks the adsorption of hydrogen on the surface. The amount of ethane formed during a temperature sweep is limited due to the loss of ethylene from the surface by desorption. Grafting ethyl species onto $\mathrm{Pd}(111)$ by reaction of ethyl iodide with the surface reveals that ethyl groups hydrogenate much more rapidly than the overall rate of ethylene hydrogenation, indicating that the addition of the first hydrogen to adsorbed ethylene is the rate-limiting step in ethylene hydrogenation. As part of this work, two ethyl iodide adsorption geometries were found. One forms at low exposures at $80 \mathrm{~K}$ in which the mirror symmetry plane of ethyl iodide is oriented close to parallel to the surface, and the other forms at high coverages where the mirror symmetry plane is oriented more closely to normal to the surface.

Acknowledgment. We gratefully acknowledge support of this work by the U.S. Department of Energy, Division of Chemical Sciences, Office of Basic Energy Sciences, under grant number DE-FG02-00ER15091. D.S. acknowledges the receipt of a dissertator fellowship from the University of WisconsinMilwaukee.

\section{References and Notes}

(1) Horiuti, I.; Polanyi, M. Trans. Faraday Soc. 1934, 30, 1164.

(2) Azad, S.; Kaltchev, M.; Stacchiola, D.; Wu, G.; Tysoe, W. T. J. Phys. Chem. 2000, B104, 3107.

(3) Ormerod, R. M.; Lambert, R. M.; Bennett, D. W.; Tysoe, W. T. Surf. Sci. 1995, 330, 1.

(4) Wu, G.; Molero, H.; Tysoe, W. T. Surf. Sci. 1998, 397, 179.
(5) Stacchiola, D.; Wu, G.; Kaltchev, M.; Tysoe, W. T. J. Chem. Phys. 2001, 115, 3315 . 145 .

(6) Kaltchev, M.; Thompson, A.; Tysoe, W. T. Surf. Sci. 1997, 391,

(7) Conrad, H.; Ertl, G.; Latta, E. E. Surf. Sci. 1974, 41, 435.

(8) Tysoe, W. T.; Nyberg, G. L.; Lambert, R. M. J. Phys. Chem. 1984, $8,1960$.

(9) Öfner, H.; Zaera, F. J. Phys. Chem. 1992, B101, 396.

(10) Shaikhutdinov, S.; Heemeier, M.; Bäumer, M.; Lear, T.; Lennon, D.; Oldman, R. J.; Jackson, S. D.; Freund, H. J. Catal. 2001, 200, 330.

(11) Somorjai, G. A. In Elementary Reaction Steps in Heterogeneous Catalysis; Joyner, R. W., Van Santen, R. A., Eds.; Kluwer: Dordrecht, 1993; p 3.

(12) Sekitani, T.; Tabooka, T.; Fujisawa, M.; Nishijima, M. J. Phys. Chem. 1992, 96, 8462.

(13) Schuit, C. G. A.; Reijen, L. L. Adv. Catal. 1958, 10, 242.

(14) Molero, H.; Stacchiola, D.; Tysoe, W. T. In preparation.

(15) Molero, H.; Bartlett, B. F.; Tysoe, W. T. J. Catal. 1999, 181, 49

(16) Zaera, F.; Somorjai, G. A. J. Am. Chem. Soc. 1984, 106, 2288.

(17) Hoffmann, H.; Griffiths, P. R.; Zaera, F. Surf. Sci. 1992, 262, 141.

(18) Crowder, G. A. J. Mol. Spectrosc. 1973, 48, 467.

(19) During, J. R.; Thompson, J. W.; Thyagesan. J. W.; Witt, J. D. J. Mol. Struct. 1975, 24, 41

(20) Redhead, P. A. Vacuum 1962, 12, 203.

(21) Herzberg, G. Infrared and Raman Spectra; Van Nostrand Reinhold Company: New York, 1945.

(22) Tysoe, W. T.; Nyberg, G. L.; Lambert. R. M. J. Phys. Chem. 1984 88,1960 .

(23) Wang, L. P.; Tysoe, W. T.; Hoffmann, H.; Zaera, F.; Ormerod, R.

M.; Lambert, R. M. Surf. Sci. 1990, 94, 4236.

(24) Ferrero, J. R.; Ziomek, J. S. Introductory Group Theory; Plenum Press: New York, 1976.

(25) Bradshaw, A. M.; Hoffmann, F. M. Surf. Sci. 1978, 72, 513.

(26) Cremer, P. S.; Su, X.; Shen, R.; Somorjai, G. A. J. Am. Chem. Soc. 1996, 118, 2942

(27) Fan, J.; Trenary, M. Langmuir 1994, 10, 3649.

(28) Backx, C.; de Groot, C. P. M.; Biloen, P. Appl. Surf. Sci. 1980, 6, 556.

(29) Backx, C.; de Groot, C. P. M. Surf. Sci. 1982, 115, 382.

(30) Stacchiola, D.; Wu., G.; Kaltchev, M.; Tysoe, W. T. Surf. Sci. 2001 $486,9$.

(31) Akita, M.; Osaka, N.; Hiramoto, S.; Itoh, K. Surf. Sci. 1999, 427/ $428,374$.

(32) Gates, J. A.; Kesmodel, L. L. Surf. Sci. 1982, 120, L461.

(33) Neurock, M.; Van Santen, R. A. J. Phys. Chem. 2000, B104, 1127.

(34) Kubota, J.; Ichihara, S.; Kondo, J. N.; Domem, K.; Hirose, C. Langmuir 1996, 12, 1926.

(35) Kubota, J.; Ohtani, T.; Kondo, J. K.; Hirose, C.; Domem, C. Appl. Surf. Sci. 1997, 121/122, 548.

(36) Merril, P. B.; Madix, R. J. J. Am. Chem. Soc. 1996, 118, 5062.

(37) Stacchiola, D.; Wu, G.; Molero, H.; Tysoe, W. T. Catal. Lett. 2001, 71,1

(38) Ormerod, R. M.; Lambert, R. M.; Hoffmann, H.; Zaera, F.; Wang, L. P.; Bennett, D. W.; Tysoe, W. T. J. Phys. Chem. 1994, 98, 2134.

(39) Kesmodel, L. L.; Dubois, L. H.; Somorjai, G. A. J. Chem. Phys. 1979, 70, 2180.

(40) Anderson, A. B.; Choe, S. J. J. Phys. Chem. 1989, 93, 6145.

(41) Zaera, F. Surf. Sci. 1989, 219, 453.

(42) Zaera, F. J. Phys. Chem. 1990, 94, 8350.

(43) Zaera, F.; Sariwan, T.; Janssens, T. V. W. Langmuir 1998, 14 , 1320 